\title{
Reabilitação do Sítio Histórico Urbano de Bauru
}

Urban Rehabilitation - Historical Site of Bauru

Rehabilitación Urbana - Sitio Histórico de Bauru

Viviane Gasparini Mota Discente, FAAC - UNESP, Brasil vi.gasparinimota@gmail.com

Rafael Neves de Oliveira Discente, FAAC - UNESP, Brasil rafaelnevesdeoliveira@gmail.com

\section{Rosío Fernandez Baca Salcedo}

Docente, FAAC - UNESP, Brasil rosiofbs@faac.unesp.br 


\section{RESUMO}

O centro urbano de Bauru apresenta uma crescente concentração do comércio, serviços e finanças, em detrimento da função residencial, com funcionamento apenas no horário comercial, configurando uma área insegura e degradada. O Sítio Histórico Urbano de Bauru (SHUB), localizada neste centro, abriga uma alta concentração de edifícios tombados pelo Conselho de Defesa do Patrimônio Histórico, Artístico, Arqueológico e Turístico do Estado de São Paulo (CONDEPHAAT) e pelo Conselho de Defesa do Patrimônio Cultural do Município de Bauru (CODEPAC), alguns edifícios sem uso ou com uso parcial. O SHUB é afetado por processos de degradação urbana e apresenta espaços com características diversificadas, de nível físico, social, econômico e funcional, nos quais se condensam problemáticas específicas que exigem ações diferenciadas. Neste contexto, o objetivo do trabalho é compreender e analisar o Sítio Histórico Urbano de Bauru (SHUB) a partir de quatro eixos temáticos: Moradia Social, Transporte, História e Cultura e, Meio Ambiente; e propor diretrizes projetuais para sua requalificação urbana. As propostas projetuais para o SHUB, a partir da integração de quatro eixos temáticos, pretendem: retomar seu caráter de centro urbano ativo, valorizar o patrimônio, reabilitar os edifícios com usos 24 horas (moradia, cultura), criar espaços públicos com qualidade, segurança e mobilidade.

PALAVRAS-CHAVE: Bauru. Sítio Histórico Urbano. Reabilitação Urbana. Patrimônio.

\section{ABSTRACT}

The urban center of Bauru presents an increasing concentration of commerce, services and finances, to the detriment of the residential function, functioning only during business hours, forming an unsafe and degraded area. The Historic Urban Site of Bauru (HUSB), located in this center, houses a high concentration of buildings listed by the Council for the Defense of Historic, Artistic, Archaeological and Tourist Patrimony of the State of São Paulo (CONDEPHAAT) and by the Council for the Defense of Cultural Heritage of the Municipality of Bauru (CODEPAC), some buildings without use or with partial use. The HUSB is affected by processes of urban degradation and presents spaces with diversified characteristics, of physical, social, economic and functional level, in which specific problems that require different actions are condensed. In this context, the objective of this work is to understand and analyze the Historic Urban Site of Bauru (HUSB) from four thematic axes: Social Housing, Transportation, History and Culture and Environment; and to propose design guidelines for its urban requalification. Project proposals for HUSB, based on the integration of four thematic axes, aim to: retake its character as an active urban center, enhance its heritage, rehabilitate buildings with 24 hour use (housing, culture), create public spaces with quality, security and mobility.

KEY WORDS: Bauru. Historic Urban Site. Urban Rehabilitation. Patrimony.

\section{RESUMEN}

El centro urbano de Bauru presenta una creciente concentración del comercio, servicios y finanzas, en detrimento de la función residencial, con funcionamiento sólo en el horario comercial, configurando un área insegura y degradada. El Sitio Histórico Urbano de Bauru (SHUB), ubicado en este centro, alberga una alta concentración de edificios tomados por el Consejo de Defensa del Patrimonio Histórico, Artístico, Arqueológico y Turístico del Estado de São Paulo (CONDEPHAAT) y por el Consejo de Defensa del Patrimonio Cultural del municipio de Bauru (CODEPAC), algunos edificios sin uso o con uso parcial. El SHUB es afectado por procesos de degradación urbana y presenta espacios con características diversificadas, de nivel físico, social, económico y funcional, en los que se condensan problemáticas específicas que exigen acciones diferenciadas. En este contexto, el objetivo del trabajo es comprender y analizar el Sitio Histórico Urbano de Bauru (SHUB) a partir de cuatro ejes temáticos: Vivienda Social, Transporte, Historia y Cultura y Medio Ambiente; y proponer directrices proyectivas para su recalificación urbana. Las propuestas proyectuales para el SHUB, a partir de la integración de cuatro ejes temáticos, pretenden: retomar su carácter de centro urbano activo, valorar el patrimonio, rehabilitar los edificios con usos 24 horas (vivienda, cultura), crear espacios públicos con calidad, seguridad y movilidad.

PALABRAS CLAVE: Bauru. Sitio Histórico Urbano. Rehabilitación Urbana. Patrimonio. 


\section{INTRODUÇÃO}

Os processos de urbanização, planejamento urbano e políticas públicas modificam os espaços e seus usos na cidade. $O$ centro tradicional - antes considerado representante da centralidade e acomodando uma rede de serviços e comércio - agora se multiplica em mais de um ponto para atender à demanda e diminuir as distâncias que o crescimento urbano produz. A degradação do antigo centro se dá a partir do desenvolvimento de outras áreas, que absorvem suas funções e cria novas, adaptadas às necessidades atuais (BOTELHO, 2005; BRIGHT, 2000).

O município de Bauru, localizado no centro oeste paulista, apresenta a área total de 667,684 $\mathrm{km}^{2}$ e população estimada em torno de 374 mil pessoas, em 2018 (IBGE, 2010). A região foi ocupada em 1856, apoiada inicialmente na produção de café e posteriormente na pecuária e cana de açúcar (SALOMÃO, 1994; SANTOS, 2007). A cafeicultura estimulou o desenvolvimento das ferrovias pela necessidade de escoamento da produção. Com o estabelecimento da ferrovia a partir de $1905 \mathrm{com}$ as Estradas de Ferro Sorocabana (1905), Noroeste (1906) e Paulista (1910), o transporte ferroviário ganhou destaque regional e Bauru passou a conter o principal entroncamento ferroviário do Brasil (ESTAÇõES FERROVIÁRIAS, 2018).

Com a instalação das ferrovias, o crescimento da cidade de Bauru se deu a partir da conformação de um eixo comercial formado pelas Ruas Batista de Carvalho, 10 de Agosto e Av. Rodrigues Alves, além da Praça Machado de Mello, que era o ponto de paragem de passageiros que embarcariam na Estação Ferroviária Noroeste do Brasil (CORGHI, 2008). Já em 1930, a cidade se encontra como pólo urbano regional de prestação de serviço e sua população, antes com 600 habitantes durante a implantação da ferrovia, se duplica.

Atualmente, o centro urbano de Bauru concentra o comércio, serviços e as finanças, em detrimento da função residencial. Muitos dos pavimentos térreos das construções existentes foram reformados para adequá-los ao comércio e serviço, perdendo sua tipologia original, também, as esquadrias de madeira foram substituídas por portas metálicas.

O centro urbano de Bauru é parcialmente ocupado, durante o funcionamento do horário comercial, das 9 h00 às 18h00, após este horário, as ruas ficam vazias e inseguras, principalmente as ruas Batista de Carvalho, 10 de Agosto, Av. Rodrigues Alves.

O centro urbano apresenta edificações representativas das expressões sociais, culturais, políticas e tecnológicas, dos diferentes períodos históricos pelas que passou a cidade, arquiteturas ecléticas, art deco, art noveau, modernas, edificações representativas com valor histórico, arquitetônico e cultural, tombadas pelo Conselho de Defesa do Patrimônio Histórico, Artístico, Arqueológico e Turístico do Estado de São Paulo (CONDEPHAAT) e pelo Conselho de Defesa do Patrimônio Cultural do Município de Bauru (CODEPAC). A concentração das edificações tombadas pelo CONDEPHAAT e CONDEPAC constituem o Sítio Histórico Urbano de Bauru (SHUB). O Sítio Histórico Urbano é definido, segundo a Carta de Petrópolis de 1987, como no espaço que concentra testemunhos do fazer cultural da cidade em suas diversas manutenções. 
Essas construções estão em parte abandonadas e outras em uso, no entanto, todas elas se encontram de regular a péssimo estado de conservação, evidenciados pelo desuso e pelo descaso dos proprietários, das Instituições de preservação e da gestão pública. No entanto, essas construções apresentam grande potencial de uso, tanto para moradia quanto para demais atividades complementares para o entorno. Diante do abandono, degradação das edificações e de sua importância histórica, arquitetônica dessas edificações há necessidade de requalificar a área do sítio histórico urbano.

\section{OBJETIVOS}

O objetivo do trabalho é compreender e analisar o Sítio Histórico Urbano de Bauru (SHUB) a partir dos eixos temáticos de Moradia Social, Transporte, História e Cultura e, Meio Ambiente; e propor diretrizes projetuais para sua requalificação urbana.

\section{MÉTODO}

A requalificação do sítio histórico urbano de Bauru compreende 3 etapas. Primeira, a delimitação do SHUB. Segunda, a análise dos 4 eixos temáticos Moradia Social, Transporte, História e Cultura e, Meio Ambiente. E terceira, a proposta de reabilitação do SHUB com base nos 4 eixos temáticos.

O SHUB foi definido a partir da concentração de edifícios tombados pelo CONDEPAC e CONDEPHAAT, localizados na área central. Esta área compreende o perímetro entre a Avenida Rodriges Alves, Avenida Nações Unidas, Avenida Pedro de Toledo e a Rua Presidente Kennedy. O estudo e a análise do SHUB é realizada através de 4 eixos temáticos: História e Cultura (fatos históricos relevantes da cidade), Moradia Social (usos do solo, com ênfase na habitação), Meio ambiente (a vegetação existente nos espaços públicos) e Transporte coletivo (as linhas de transporte suas rotas).

As plantas e mapas históricos foram cedidos pela Prefeitura Municipal de Bauru. Em seguida, para conhecer a área definida como SHUB e suas relações dinâmicas com o entorno, foram realizadas uma série de visitas in loco, identificando as características mais relevantes da região. A partir de então, para organizar e qualificar as informações levantadas, foram produzidos mapas, imagens e tabelas demarcando pontos de interesse a respeito da estrutura e da paisagem urbana com base nas visitas realizadas e através de fotografias aéreas disponibilizadas pela Prefeitura e imagens complementares do Google Earth e Google Maps. $\mathrm{O}$ mapa de base para a produção das cartografias foi fornecido pela Prefeitura no formato .dwg do software AutoCad. As imagens por sua vez, foram produzidas no programa Photoshop da empresa Adobe.

Em seguida, consiste a análise dos dados obtidos tanto por meio de referências e leis quanto através do material produzido, com o intuito de ter uma compreensão da distribuição espacial, localização e situação dos edifícios históricos, equipamentos públicos, da arborização urbana, pontos de alagamento e erosão, presença de transporte público e pontos de ônibus, 
acessibilidade, mobilidade, principais fluxos de pessoas e veículos, estrutura da paisagem e a dinâmica do bairro. A proposta de reabilitação do SHUB é realizada a partir da análise dos 4 eixos temáticos, visando a preservação das edificações tombadas, da melhoria da qualidade de vida e da permanência das pessoas no sítio histórico urbano a partir da proposta de moradia e de usos de comércio e serviços 24 horas, adequadas as necessidades e características da zona de intervenção.

\section{RESULTADOS}

Os resultados do SHUB são apresentados a partir dos eixos temáticos de História e Cultura Transporte, Meio Ambiente e Moradia Social.

\section{História e Cultura}

A partir de 1886, a chegada de imigrantes assume um caráter importante para o estado de São Paulo, com mais de dez mil estrangeiros registrados, os quais entorno de 1/4 desembarcaram na região noroeste do estado (PINHEIRO, 1928). Nesse contexto, pode-se relatar que a construção da Estrada de Ferro Noroeste do Brasil, em 1906, ligando as cidades de Bauru (SP) e Corumbá (MS), introduziu toda a região oeste do estado de São Paulo ao sistema agroexportador e ao povoamento, além de integrar e dinamizar as economias do atual estado de Mato Grosso do Sul e do Mato Grosso. Durante a primeira década do século XX, além da Noroeste, também foram implantadas a Estrada de Ferro da Sorocabana em 1905 e a Estrada de Ferro Paulista, em 1910, fizeram de Bauru um entroncamento do transporte ferroviário de passageiros e cargas. A cidade passou a ser um importante pólo comercial e de serviços de escala regional. Matos (1990) relata sobre o valor da ferrovia para as cidades:

A chegada dos trilhos é quase sempre um marco na história de uma cidade. Com a estrada de ferro vem todo o aparelhamento que ela exige, especialmente quando a cidade, por alguma razão, é escolhida para sede de qualquer atividade especial da estrada: armazém, oficinas, escritórios, ponto de cruzamento de trens ou local de baldeação (MATOS, 1990, p.197).

A Estrada de Ferro Noroeste do Brasil, ao contrário de suas antecessoras que surgiram para auxiliar a produção cafeeira já existente, abriu novos territórios para o cultivo do café e para o povoamento no oeste paulista. Na medida em que a ferrovia penetrava no sertão, em toda a região a oeste de Bauru, surgiam estações e, ao redor de cada uma, instalaram-se povoados. Algumas cidades que se formaram a partir destes povoados são: Avaí, Presidente Alves, Cafelândia, Lins, Promissão, Avanhandava, Penápolis, Glicério, Birigui e Araçatuba.

O processo de parcelamento da área da cidade de Bauru durante o século 20 se deu a partir da iniciativa privada com a divisão das glebas das antigas fazendas, no mesmo período em que teve início a implementação das estradas de ferro. A Área Central juntamente com a Zona de Interesse Histórico Cultural (BAURU, 2008) compreendem uma gleba originária da Fazenda das Flores (Figura 1). 


\section{REVISTA CIENTÍFICA}

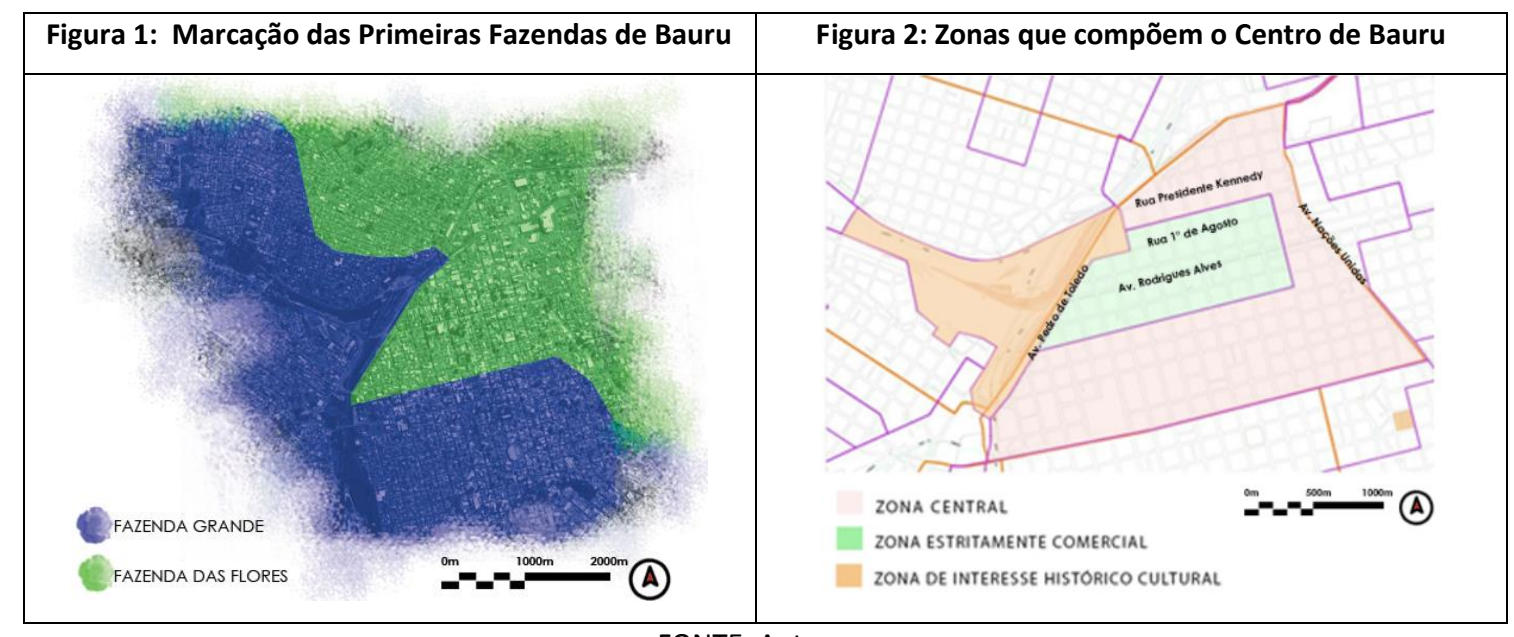

FONTE: Autores.

A Estação Ferroviária da NOB, bem como os hotéis localizados nas imediações, foram os protagonistas do desenvolvimento da cidade, construindo uma rede de relações que alimentaram a vida e o fluxo no local (SALCEDO et al, 2012). Entretanto, a partir do desenvolvimento da indústria automobilística no Brasil, o transporte rodoviário ganhou espaço, levando ao decaimento das ferrovias brasileiras. Durante a década de 30, houve o crescimento comercial com edificações em dois pavimentos, sendo o comércio no térreo e a residência no andar superior. O Palacete Pagani, o Sobrado da Batista de Carvalho, a Casa Lusitana, a Farmácia Popular e a Casa Savastano são exemplos dessa tipologia. O Edifício Abelha foi uns dos primeiros edifícios exclusivamente comerciais, reforçando o caráter comercial da região. $\mathrm{A}$ Casa Ponce Paz foi construída em 1938, servindo como residência, mas passou por diversas reformas e apresenta diferentes estilos arquitetônicos e, atualmente o local pertence a Secretaria Municipal da Cultura para tornar-se a Pinacoteca de Artes de Bauru. O Edifício INSS foi considerado um dos principais representantes da nova fase de crescimento urbano na década de 70 em Bauru, reforçando o auge do estilo modernista característico da cidade. 0 núcleo da região, representado pelos hotéis Cariani, Estoril e Milanesi e pela estação ferroviária, apresenta hoje aspecto degradado e até mesmo abandonado. Sem incentivos para a salvaguarda do patrimônio histórico, o local que outrora foi o mais movimentado, hoje encontra-se como a área mais vazia do centro, tendo sua ocupação apenas durante o horário comercial.

A área como um todo é afetada por processos de degradação urbana e apresenta espaços com características diversificadas, de nível físico, social, econômico e funcional, nos quais se 


\section{REVISTA CIENTÍFICA}

condensam problemáticas específicas que exigem ações diferenciadas. As antigas edificações foram substituídas ou adaptadas gradativamente por estabelecimentos comerciais. Pela ausência de equipamentos, atividades culturais e serviços noturnos, quando o dia acaba, a vida se extingue também. Pela situação de abandono, é comum encontrar ocupações irregulares de forma precária nesses espaços esquecidos e ao longo da ferrovia. A região central possui diversos edifícios abandonados em estado de deterioração, desde a pintura até elementos estruturais. Essas construções apresentam um grande potencial de uso, tanto para moradia quanto para demais atividades complementares para o entorno.

A área delimitada como Sítio Histórico Urbano de Bauru (SHUB) concentra uma série de edifícios históricos que representam a memória de toda uma construção histórica e cultural realizada por um povo, especificamente da formação da cidade, mas que foram esquecidos no tempo e que a população desconhece de sua importância histórica por não existir nenhuma informação visível e de fácil acesso, sendo apenas reconhecidos pelas gerações mais velhas que conviveram com tais edificações durante seu período de funcionamento ou pelas demais somente por suas aparências de prédios antigos e degradados pelo tempo. A figura 3 apresenta o perímetro do SHUB. Também, parte de estas edificações encontram-se parcial ou totalmente abandonadas, o que leva ao processo de sua degradação (Figura 4) a localização das edificações tombadas pelo CODEPAC e CONDEPHAAT.

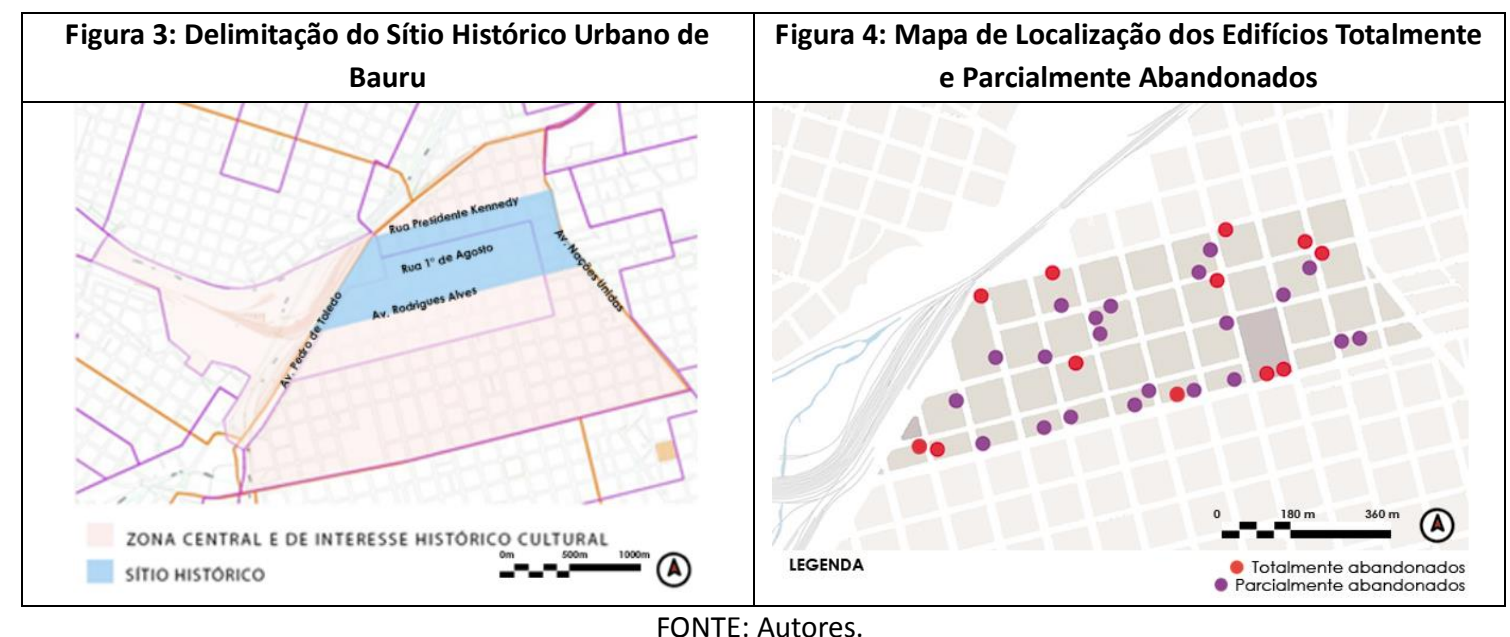

Os edifícios tombados, pelo órgão municipal CODEPAC representam a formação da cidade. A Estação Ferroviária da NOB, bem como os hotéis localizados nas imediações, foram os protagonistas do desenvolvimento da cidade, construindo uma rede de relações que alimentaram a vida e o fluxo no local. Nesse contexto, a Casa do Superintendente da NOB, marcou a construção de edificações residenciais na região, com as primeiras casas para os trabalhadores da ferrovia. O Edifício INSS foi considerado um dos principais representantes da 


\section{REVISTA CIENTÍFICA 2018}

nova fase de crescimento urbano na década de 70 em Bauru, reforçando o auge do estilo modernista característico da cidade (Figura 5).

Figura 5: Mapa de Localização dos Edifícios Tombados

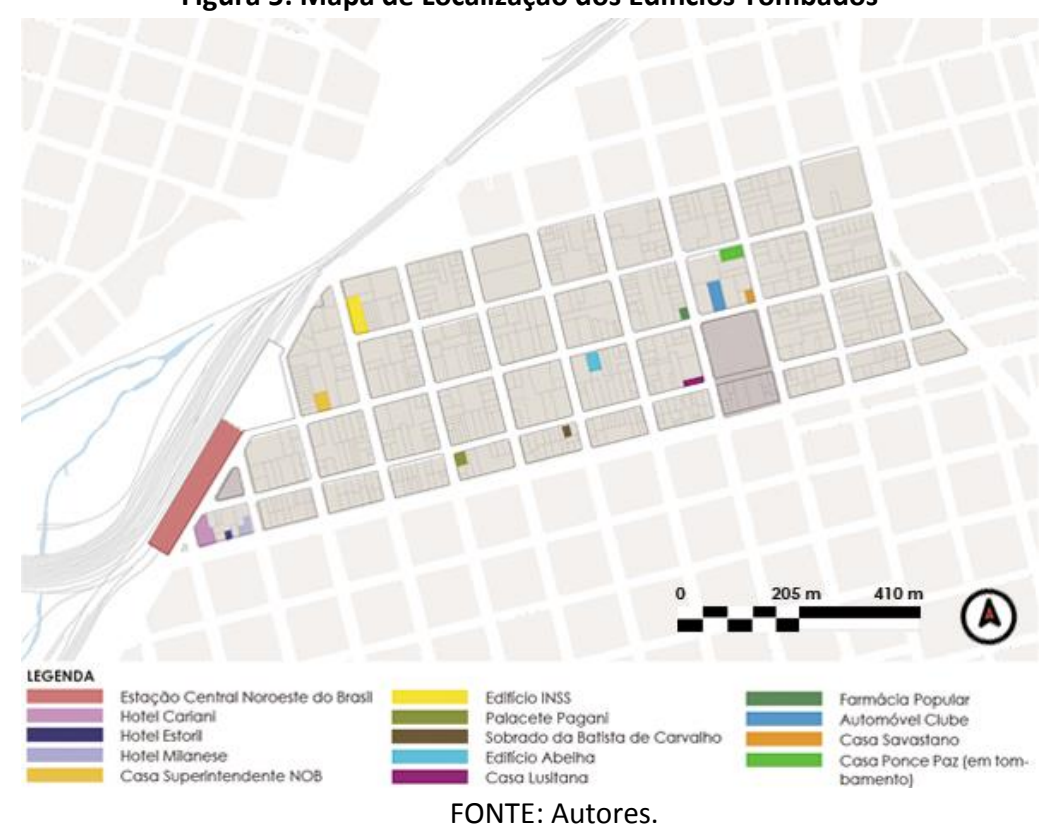

O SHUB abriga 14 edificações tombadas pelo CONDEPHAAT e CODEPAC, que representam as expressões históricas, sociais, culturais, políticas e tecnológicas da sociedade (Quadro 1).

Quadro 1: Levantamento dos edifícios tombados.

\begin{tabular}{|c|c|c|c|c|c|c|}
\hline Nome & Localização & $\begin{array}{c}\text { Ano de } \\
\text { Construção }\end{array}$ & Tombamento & Uso original & Uso Atual & Foto \\
\hline $\begin{array}{l}\text { Estação } \\
\text { Ferroviária } \\
\text { NOB }\end{array}$ & $\begin{array}{l}\text { Praça Machado } \\
\text { de Mello, 3-95 }\end{array}$ & 1939 & $\begin{array}{c}\text { Decreto } 8.617 \text { de } \\
28 / 10 / 1999\end{array}$ & Transporte & $\begin{array}{l}\text { Eventos } \\
\text { singulares }\end{array}$ & 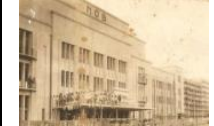 \\
\hline Hotal Cariani & $\begin{array}{l}\text { Praça Machado } \\
\text { de Mello, no 1- } \\
2\end{array}$ & 1921 & $\begin{array}{c}\text { Decreto } 9.306 \text { de } \\
22 / 10 / 2002\end{array}$ & Hotel & $\begin{array}{l}\text { Fechado ou } \\
\text { Abandonado }\end{array}$ & îf \\
\hline Hotel Estoril & $\begin{array}{l}\text { Av. Rodrigues } \\
\text { Alves, 2-41 }\end{array}$ & 1912 & $\begin{array}{c}\text { Decreto } 9.593 \text { de } \\
20 / 10 / 2003\end{array}$ & Hotel & $\begin{array}{l}\text { Fechado ou } \\
\text { Abandonado }\end{array}$ & 9 \\
\hline $\begin{array}{c}\text { Hotel } \\
\text { Milanese }\end{array}$ & $\begin{array}{l}\text { Av. Rodrigues } \\
\text { Alves, 2-77 }\end{array}$ & 1915 & $\begin{array}{c}\text { Decreto } 9.548 \text { de } \\
10 / 09 / 2003\end{array}$ & Hotel & $\begin{array}{c}\text { Fechado ou } \\
\text { Abandonado }\end{array}$ & 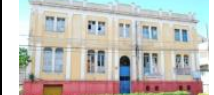 \\
\hline $\begin{array}{l}\text { Casa } \\
\text { Superintend } \\
\text { ente }\end{array}$ & $\begin{array}{l}\text { R. } 1^{\circ} \text { de Agosto, } \\
2-31\end{array}$ & 1920 & $\begin{array}{c}\text { Decreto } 9.459 \mathrm{de} \\
5 / 06 / 2003\end{array}$ & Residência & Escritório & \\
\hline
\end{tabular}




\section{REVISTA CIENTÍFICA 2018}

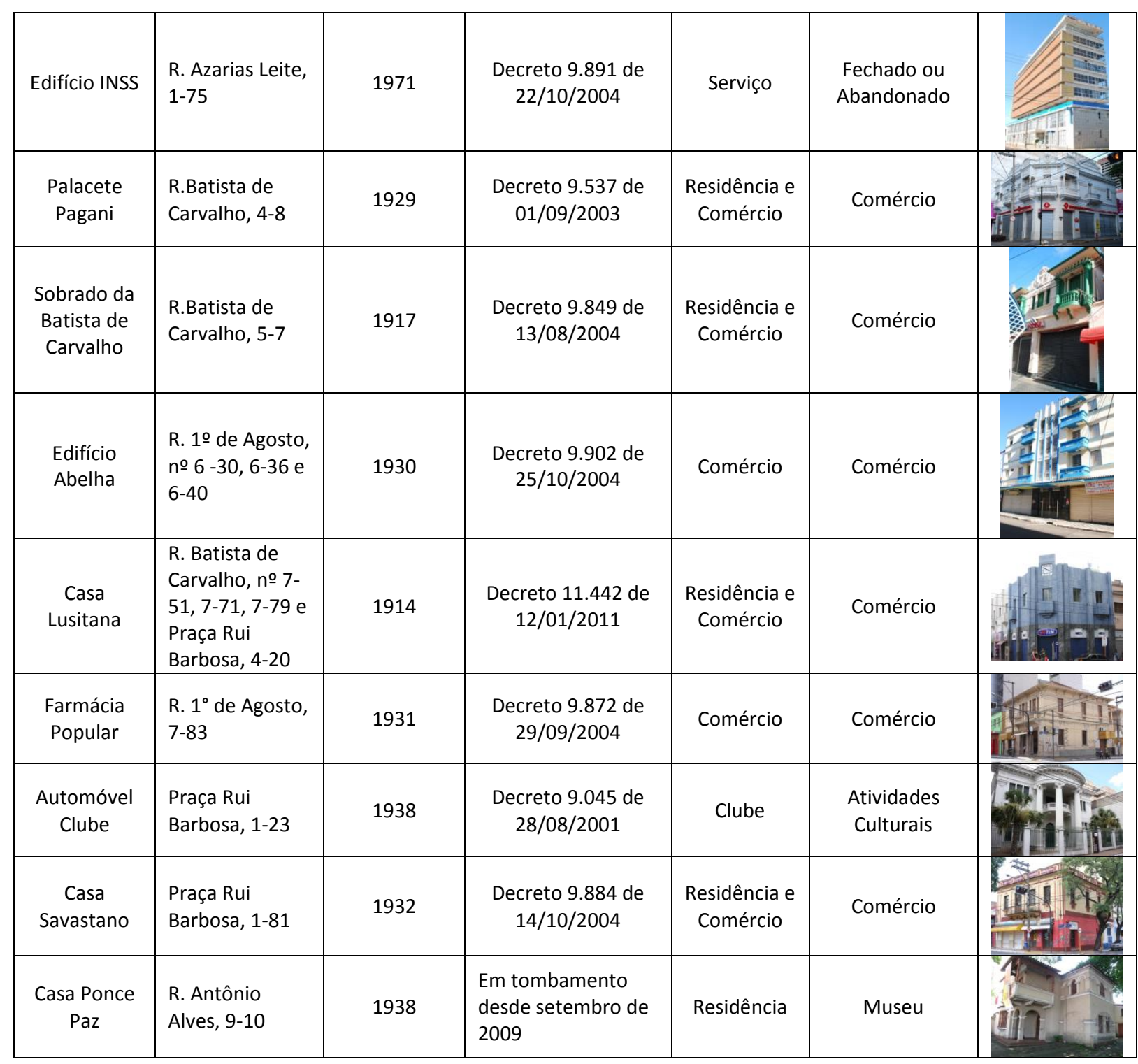

FONTE: Autores.

\section{Transporte}

A ocupação do centro consolidado de Bauru, envolveu a conjunção dos agentes econômicos, institucionais, físicos e relações sociais, diferidos ao longo do tempo. Segundo VUCHIC (1981), a ocupação do espaço urbano depende das relações econômicas dominantes num determinado período produzindo uma determinada distribuição de atividades e diferentes padrões de intensidade e uso. Por condensar toda a atividade comercial por um longo período, a intensidade e os deslocamento das pessoas definiu o sistema de transporte que se adaptou ao longo do tempo. A cidade teve seu crescimento inicial apoiado no transporte ferroviário, 


\section{REVISTA CIENTÍFICA}

permitindo o desenvolvimento comercial nos arredores da Estação Ferroviária Noroeste do Brasil.

Entretanto, a partir do progresso ocorrido pós a Segunda Guerra mundial, o transporte individual passou para primeiro plano, levando ao desenvolvimento rodoviário, negligenciando o transporte em massa pelas ferrovias (ALTSHULER, 1979). O mesmo aconteceu em Bauru que atualmente concentra grande fluxo de pessoas e veículos durante o horário de funcionamento. Porém, com o automóvel no topo da hierarquia viária, existe uma disputa de espaços para circulação do transporte individual e público (ônibus), ignorando as necessidades e a importância do pedestre. $O$ resultado disso é a concentração do transporte público, 22 linhas de transporte, na principal avenida de acesso a região, Av. Rodrigues Alves, transformando-a em um terminal a céu aberto (Quadro 2). O que se observa são pontos de ônibus incapazes de suportar a quantidade de pessoas com deficiência de infraestrutura gerando aglomerações nas calçadas impedindo o fluxo de pessoas (Figura 6).

Figura 6: Pontos e Linhas de Õnibus na Av. Rodrigues Alves

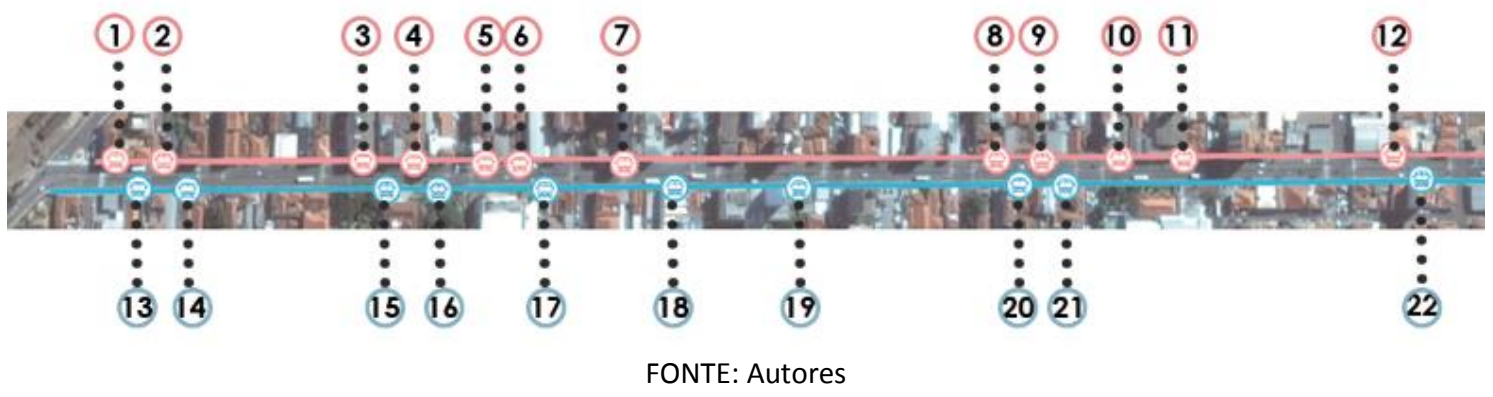


Quadro 2: Relação da Quantidade de Pontos de Ônibus e Número de Linhas na Av. Rodrigues Alves

\begin{tabular}{|c|c|c|}
\hline Identificação do Ponto de Ônibus & Sentido & Quantidade de Linhas \\
\hline 1 & Bairro - Centro & 8 \\
\hline 2 & Bairro - Centro & 7 \\
\hline 3 & Bairro - Centro & 7 \\
\hline 4 & Bairro - Centro & 6 \\
\hline 5 & Bairro - Centro & 9 \\
\hline 6 & Bairro - Centro & 7 \\
\hline 7 & Bairro - Centro & 4 \\
\hline 8 & Bairro - Centro & 8 \\
\hline 9 & Bairro - Centro & 8 \\
\hline 10 & Bairro - Centro & 7 \\
\hline 11 & Bairro - Centro & 7 \\
\hline 12 & Bairro - Centro & 11 \\
\hline 13 & Centro - Bairro & 10 \\
\hline 14 & Centro - Bairro & 2 \\
\hline 15 & Centro - Bairro & 9 \\
\hline 16 & Centro - Bairro & 7 \\
\hline 17 & Centro - Bairro & 19 \\
\hline 18 & Centro - Bairro & 5 \\
\hline 19 & Centro - Bairro & 11 \\
\hline 20 & Centro - Bairro & 17 \\
\hline 21 & Centro - Bairro & 7 \\
\hline 22 & Centro - Bairro & 15 \\
\hline
\end{tabular}

\section{Meio ambiente}

No SHUB a presença de vegetação é indispensável para a manutenção de um microclima saudável e agradável em espaços de permanência (LOBODA, 2005 p.131). A má qualidade e, em alguns casos, ausência da arborização no Sítio Histórico Urbano de Bauru, reforça seu caráter passageiro e de exercício intermitente, os quais regulam sua progressiva degradação e descaracterização que se evidencia no desuso, na insegurança e na insalubridade (Figura 7). 


\section{REVISTA CIENTÍFICA 2018}

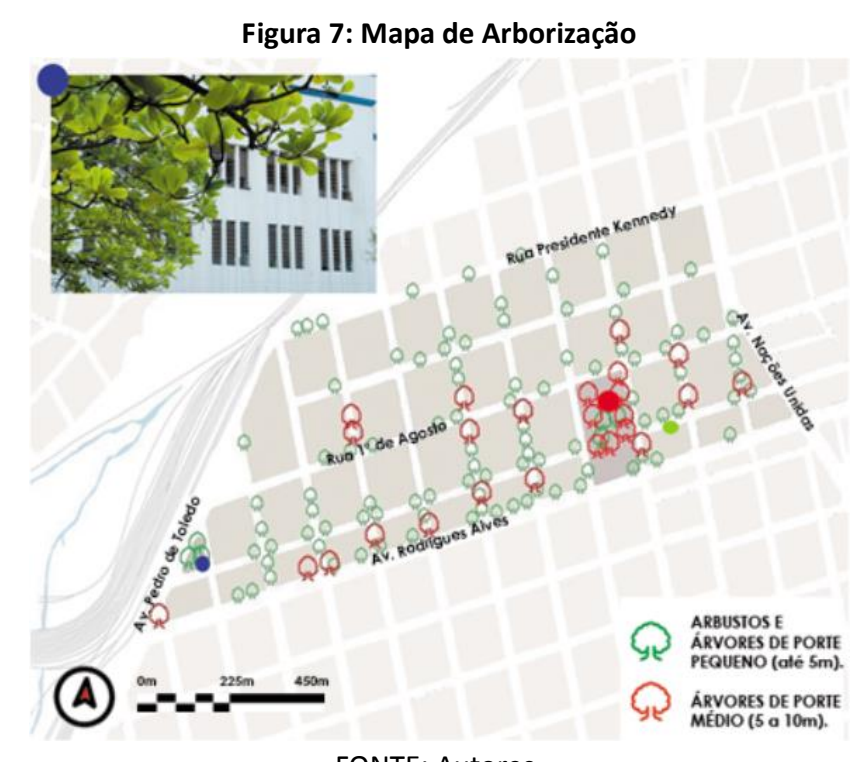

\section{Moradia}

O SHUB apresenta uma crescente concentração do comércio, serviços e finanças, em detrimento da função residencial.

Uma das principais alterações encontradas são lotes subdivididos apresentando funções comercial, serviços e residencial. Alguns estabelecimentos que apresentavam tipologias de uso misto, residências nos pavimentos superiores e o comércio no térreo, mantiveram a função comercial, mas o primeiro andar passou a servir como depósito ou em alguns casos, fechados, sem uso e em estado de degradação. Além disso, o SHUB apresenta diversos edifícios em estado de abandono e, essa condição de degradação está aliada a lógica de mercado presente na estrutura urbana e nas novas relações dinâmicas da cidade que, no caso de Bauru, a ocupação foi se deslocando para a região Sul da cidade, onde se encontram os novos eixos de verticalização (PESSOTO, 2015).

Durante a década de 90 , a região era majoritariamente caracterizada por comércio, criando assim diversos eixos e corredores comerciais, na qual o principal deles encontra-se na rua Batista de Carvalho (Figura 8) 


\section{REVISTA CIENTÍFICA 2018}

Figura 8: Mapa de Uso e Ocupação de 2018
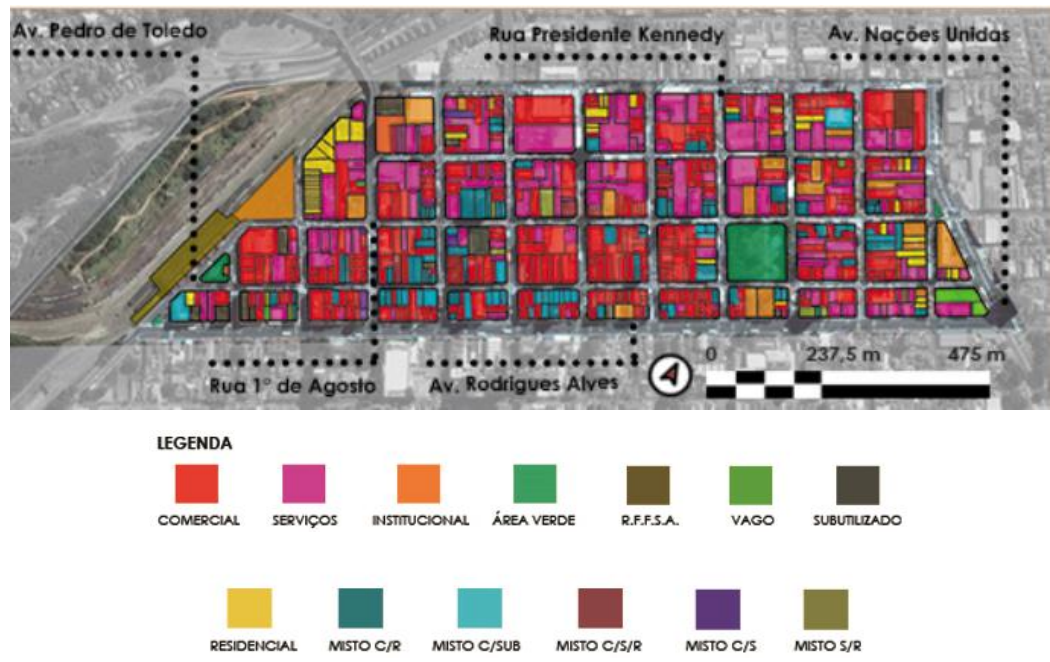

FONTE: Autores

Proposta de diretrizes projetuais para a reabilitação do Sítio Histórico Urbano de Bauru

A partir do contexto apresentado, foram desenvolvidas diretrizes para a reabilitação do SHUB com base nos 4 eixos temáticos analisados: Moradia Social, Transporte, História e Cultura e, Meio Ambiente (Figura 9). A intenção do projeto é revelar a diversidade territorial desta área e retomar seu caráter de centro urbano ativo, re-habitado, com usos 24 horas, seguro e sustentável.

A partir da integração de quatro eixos temáticos, o projeto visa a reabilitação do SHUB, foram desenvolvidas estratégias que exaltem o potencial da região, onde o foco é a escala humana e que resultem na reinserção do SHUB na paisagem urbana da cidade e na permeabilidade de seu perímetro rígido, através da criação de espaços públicos de qualidade, zonas de convívio, acesso à infraestrutura e moradia resgatando a vida e a permanência do local. Esse processo de reabilitação SHUB depende da articulação de estratégias sob responsabilidade de diferentes agentes atuando em conjunto. 


\section{REVISTA CIENTÍFICA}

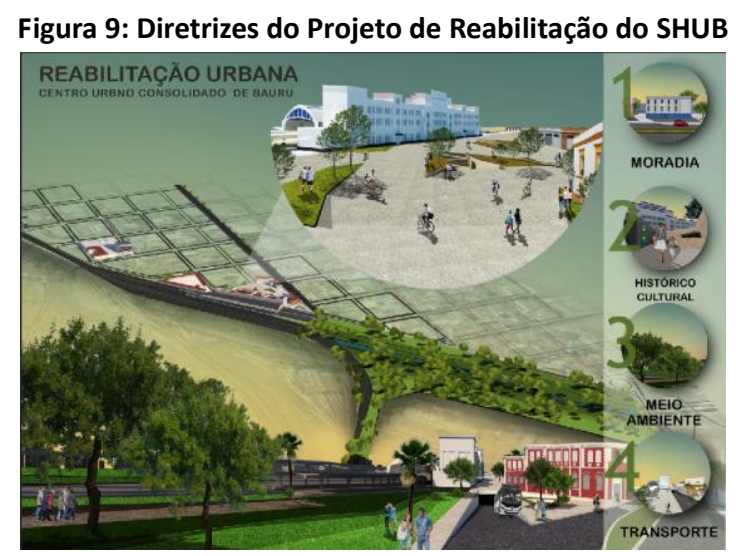

FONTE: Autores

Com o intuito de aproveitar e otimizar o espaço existente, os edifícios abandonados e o patrimônio tombado, passariam por uma reabilitação e restauração, com profissionais especializados na preservação do patrimônio histórico, de maneira a funcionarem como moradia de interesse social, sendo o público alvo, os moradores principalmente os que trabalham no centro urbano de Bauru. Os edifícios históricos selecionados são os hotéis Cariani, Estoril e Milanese e, o Edifício INSS- devido a sua localização, atualmente desocupados ou parcialmente ocupados e pela disposição dos espaços internos.

Visando a valorização do patrimônio arquitetônico tombado pelo CONDEPHAAT e CODEPACT é proposto um percurso histórico-cultural que iniciará no largo Machado de Mello, em frente ao terminal intermodal, abrangendo o patrimônio ferroviário e as construções relacionadas, como a Casa do Superintendente da NOB e as casas dos operários, os hotéis Cariani, Estoril e Milanese e o Edifício INSS (Figura 10). Além disso, o percurso inclui os edifícios abandonados de interesse projetual para expansão das atividades culturais da região e o trajeto conta com totens informativos de cada edificação e sua respectiva localização. Esse percurso se estenderá além dos limites do SHUB, atendendo os demais edifícios de importância histórica e cultural da cidade.

A proposta projetual para a mobilidade, propõe a inversão da hierarquia viária, ou seja, o sistema de transporte seria a articulação entre quatro modais: cicloviário, rodoviário, ferroviário e pedestres (Figura 10). As ações incluem a reativação da estação ferroviária articulada a um terminal intermodal subterrâneo. Dessa forma, será reduzido o fluxo de automóveis na região invertendo a situação atual. O projeto visa a implantação de um segundo calçadão na rua $1^{\circ}$ de Agosto, além da construção de um largo em frente a estação ferroviária (Figura 11). 


\section{REVISTA CIENTÍFICA $\quad 2018$}

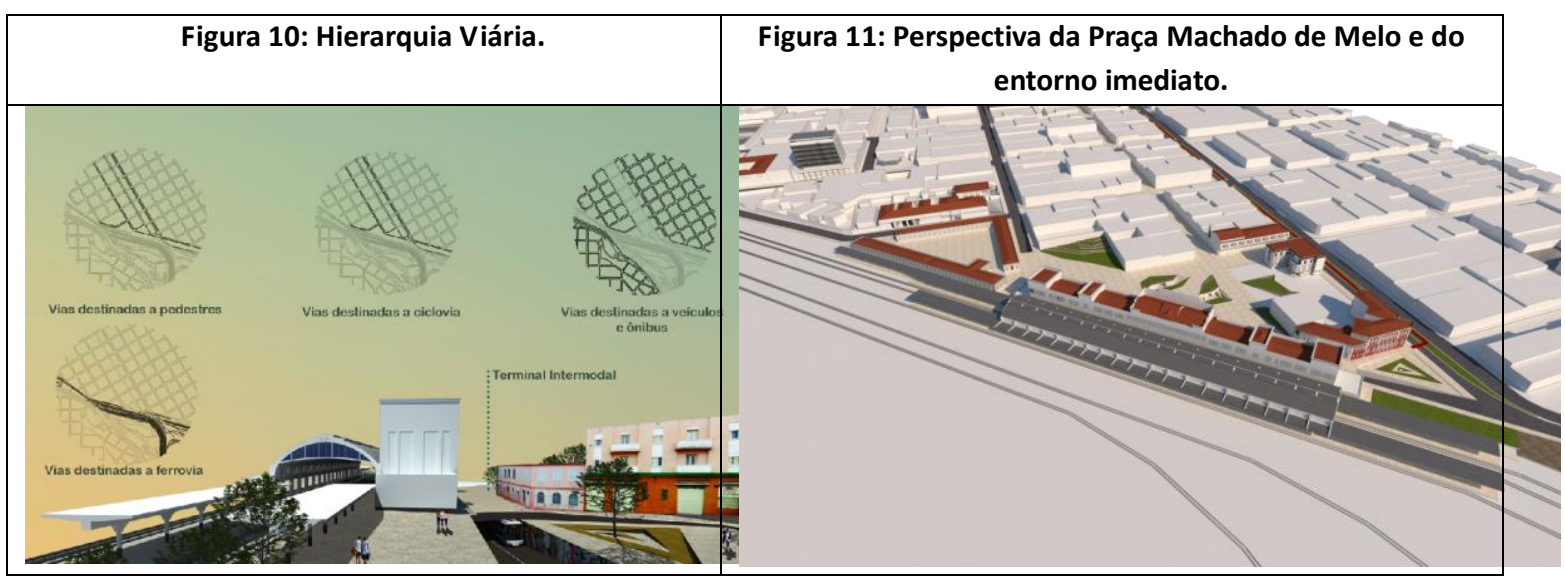

FONTE: Autores.

A proposta projetual para o meio ambiente, visa o aumento da arborização urbana a ser realizada através de uma parceria entre a Prefeitura e o Horto Florestal de Bauru, fornecendo as espécies vegetais já utilizadas no bairro para o plantio, de modo a manter a linguagem característica local e o diálogo com o entorno. Essa arborização compõe os eixos verdes e o próprio percurso histórico-cultural, além de um boulevard na Av. Rodrigues Alves, conectando os espaços até o pátio ferroviário onde será criado um bosque e ao antigo espaço da praça Machado de Mello, a qual passará por uma reformulação tranformando-se em largo (Figura 12). Esse sistema de eixos verdes serve de base para um programa de arborização urbana da cidade de Bauru.

Figura 12: Largo Machado de Mello.

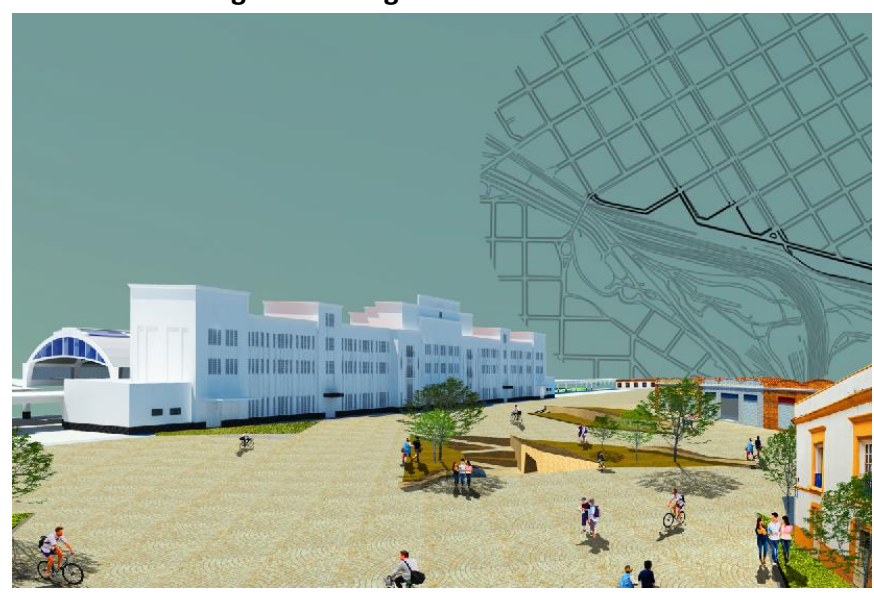

FONTE: Autores 


\section{CONCLUSÃO}

A relação do espaço público com a cidade está associada a aspectos físicos, naturais e/ou construídos, e suas características finais incluindo seu uso, formas e funções dependem da articulação política, social e econômica adotada. As relações estabelecidas no espaço não se mantém estáticas ao longo do tempo, se moldam conforme a cidade evolui e definem o tipo de apropriação (MENDONÇA, 2007). Segundo Vargas (2015) os centros urbanos seguem trajetórias semelhantes às cidades as quais pertencem, de ascenção e queda, vivenciando processos de degradação, desconstrução e desvalorização, provocados pela expansão urbana. Centros urbanos são a origem das cidades, abrigando distintas camadas cronotópicas e sedimentando as edificações ao longo do tempo, produzindo espaços carregados de história e significados.

O centro urbano de Bauru apresenta uma crescente concentração do comércio, serviços e finanças, em detrimento da função residencial, com funcionamento apenas no horário comercial, tornando-se uma área insegura e degradada. Desta maneira, percebe-se a importância do centro de Bauru, principalmente na área designada como Sítio Histórico Urbano, realizando uma análise de sua a história e patrimônio, considerando sua relação com a estrutura urbana presente de forma a compreender as reais necessidades do espaço e, proprondo sua reabilitação a partir dos quatro eixos temáticos apresentados: Moradia Social, Transporte, História e Cultura e, Meio Ambiente.

\section{REFERÊNCIAS BIBLIOGRÁFICAS}

ALTSHULER, Alan A.; WOMACK, James P.; PUCHER, John P. The Urban Transportation System: Politics and Policy Innovation Cambridge. 1979.

BAURU. Lei $n^{\circ}$ 5.631, 22 de Agosto de 2008. Prefeitura Municipal de Bauru, Bauru, SP. Plano Diretor Participativo do Município de Bauru. Disponível em: <http://hotsite.bauru.sp.gov.br/planodiretor/lei.aspx> . Acesso em: $13 / 05 / 2018$

BOTELHO, Tarcísio R. Revitalização de centros urbanos no Brasil: uma análise comparativa das experiências de Vitória, Fortaleza e São Luís. EURE (Santiago), v. 31, n. 93, p. 53-71, 2005.

BRIGHT, Elise M. (2000). Reviving America's forgotten neighborhoods. New York-London: Routledge.

CORGHI, Fernanda Nascimento et al. Urbanização e segregação socio-espacial em Bauru (SP): um estudo de caso sobre a Bacia hidrografica do Corrego da Agua Comprida. 2008.

IBGE. Instituto brasileiro de geografia e estatística, 2010. Disponível em: <https://ww2.ibge.gov.br/home/> . Acesso em: $18 / 06 / 2018$.

ERCILLA, AM de; PINHEIRO, Brenno. Estado de São Paulo: Zona Noroeste. São Paulo: Propaganda Pan-americana, 1928. 


\section{REVISTA CIENTÍFICA 2018}

ESTAÇÕES FERROVIÁRIAS DO BRASIL. Disponível em: <http://www.estacoesferroviarias.com.br> . Acesso em: 22/06/2018.

LOBODA, R. Carlos. As Áreas Verdes Públicas Urbanas: Conceitos, Usos e Funções. Guarapuava, p.131, 2005.

MENDONÇA, Eneida Maria Souza. Apropriações do espaço público: alguns conceitos. Estudos e Pesquisas em Psicologia, v. 7, n. 2, p. 0-0, 2007.

PESSOTO, Ana Paula. Bauru na vertical. JCNET. Disponível em:<http://www.jcnet.com.br/Bairros/2015/06/bauruna-vertical.html>. Acesso em: 28/10/2017.

SALCEDO, Rosio Fernández Baca et al. Vilas Ferroviarias Da Estrada De Ferro Noroeste Do Brasil (Efnob), Bauru Km. 0. 2012.

SALOMÃO, F.X. de T. Processos erosivos lineares em Bauru (SP): regionalização cartográfica aplicada ao controle preventivo urbano e Rural. Tese apresentada para a obtenção do título de doutor em Geografia. São Paulo: USP, 1994

SANTOS, J. A. dos. A produção do espaço urbano em Bauru e o direito à natureza. Qualificação apresentada ao Instituto de Geociências como parte dos requisitos para a obtenção do título de Doutor em Geografia. Campinas: Unicamp/IG, 2007.

VARGAS, Heliana Comin; DE CASTILHO, Ana Luisa Howard. Intervenções em centros urbanos: objetivos, estratégias e resultados. Editora Manole, 2015.

VUCHIC, Vukan R. Urban transit systems and technology. John Wiley \& Sons, 2007. 